\title{
Potencial terapêutico de células-tronco mesenquimais na laminite equina
}

\author{
Therapeutic potencial of mesenquimal stem cells in equine laminitis \\ Potencial terapêutico de células madre mesenquimales em laminitis equina
}

Recebido: 30/07/2021 | Revisado: 07/08/2021 | Aceito: 11/08/2021 | Publicado: 15/08/2021

\author{
Ana Beatriz dos Santos Mendes \\ ORCID: https://orcid.org/0000-0002-3647-4465 \\ Universidade Estadual do Ceará, Brasil \\ E-mail: anabia613@gmail.com \\ Ana Thays dos Santos da Silva \\ ORCID: https://orcid.org/0000-0001-7096-0080 \\ Universidade Estadual do Ceará, Brasil \\ E-mail: anathays1234@gmail.com \\ Lohane Leonel de Castro \\ ORCID: https://orcid.org/0000-0002-6454-5742 \\ Universidade Estadual do Ceará, Brasil \\ E-mail: lohane.leonel@aluno.uece.br \\ Kissya Ellen Alves da Silva \\ ORCID: https://orcid.org/0000-0002-1613-7955 \\ Universidade Estadual do Ceará, Brasil \\ E-mail: kissya.alves@aluno.uece.br \\ Marcio Gomes de Alencar Araripe \\ ORCID: https://orcid.org/0000-0002-4179-6338 \\ Universidade de Fortaleza, Brasil \\ E-mail: marcio.araripe@ yahoo.com.br
}

\begin{abstract}
Resumo
A laminite é uma doença bastante frequente na rotina clínica de equinos, que provoca, entre outros sintomas, dor e claudicação, sendo uma causa importante de eutanásia. Nesta afecção, ocorre o enfraquecimento da ligação entre o estojo córneo e a falange distal, resultando no afundamento e na rotação palmar/plantar desse osso. Diversos mecanismos estão envolvidos na patogênese da laminite, que incluem as teorias vascular, a enzimática, a traumática, a de privação de glicose e a endocrinopática, de modo que pode ocorrer secundariamente a diversas outras doenças, como cólica e doença metabólica equina. Entretanto, a compressão dos mecanismos que regem as alterações ocorridas na fisiopatologia dessa doença é bastante complexa, e ainda não está completamente elucidada. Esse fator limita o desenvolvimento de terapias eficazes para a cura da laminite. O diagnóstico pode ser feito por meio da avaliação do histórico do animal, sinais clínicos, exame físico e dos exames complementares, como radiografia, bloqueios anestésicos, venografia, termografia, entre outros métodos. A terapia deve envolver o controle da dor e estabilização do tecido laminar, e varia de acordo com o estágio de desenvolvimento da doença, principalmente, as fases aguda e crônica. Dessa forma, a medicina regenerativa, que inclui a utilização de células-tronco mesenquimais, tem ganhado bastante destaque nos últimos anos, uma vez que apresenta uma influência positiva na cura de várias lesões ortopédicas em equinos.
\end{abstract}

Palavras-chave: Equino; Laminite; Células-tronco mesenquimais.

\begin{abstract}
Laminitis is a very common disease in the clinical routine of horses, which causes, among other symptoms, pain and lameness, being an important cause of euthanasia. In this condition, there is a weakening of the connection between the horny case and the distal phalanx, resulting in the sinking and palmar / plantar rotation of this bone. Several mechanisms are involved in the pathogenesis of laminitis, which include vascular, enzymatic, traumatic, glucose deprivation and endocrinopathic theories, so that it can occur secondarily to several other diseases, such as colic and equine metabolic disease. However, the compression of the mechanisms that govern changes in the pathophysiology of this disease is quite complex, and is not yet fully understood. This factor limits the development of effective therapies for curing laminitis. The diagnosis can be made through the evaluation of the animal's history, clinical signs, physical examination and complementary exams, such as radiography, anesthetic blocks, venography, thermography, among other methods. Therapy should involve pain control and stabilization of laminar tissue, and varies according to the stage of development of the disease, especially the acute and chronic phases. Thus, regenerative medicine, which includes the use of mesenchymal stem cells, has gained considerable prominence in recent years, since it has a positive influence on the cure of various orthopedic injuries in horses.
\end{abstract}

Keywords: Equine; Laminitis; Mesenchymal stem cells. 


\begin{abstract}
Resumen
La laminitis es una enfermedad muy común en la rutina clínica de los caballos, que provoca, entre otros síntomas, dolor y cojera, y es una importante causa de eutanasia. En esta condición, hay un debilitamiento de la conexión entre la caja corneal y la falange distal, lo que resulta en el hundimiento y la rotación palmar / plantar de este hueso. Varios mecanismos están involucrados en la patogenia de la laminitis, incluyendo teorías vasculares, enzimáticas, traumáticas, de privación de glucosa y endocrinopáticas, por lo que puede ocurrir como consecuencia de varias otras enfermedades, como los cólicos y la enfermedad metabólica equina. Sin embargo, la compresión de los mecanismos que gobiernan los cambios que se producen en la fisiopatología de esta enfermedad es bastante compleja, y aún no se ha dilucidado por completo. Este factor limita el desarrollo de terapias efectivas para curar la laminitis. El diagnóstico se puede realizar mediante la evaluación de la historia del animal, signos clínicos, exploración física y pruebas complementarias, como radiografía, bloqueos anestésicos, venografía, termografía, entre otros métodos. La terapia debe implicar el control del dolor y la estabilización del tejido laminar, y varía según el estadio de desarrollo de la enfermedad, especialmente las fases aguda y crónica. Así, la medicina regenerativa, que incluye el uso de células madre mesenquimales, ha ganado un protagonismo considerable en los últimos años, ya que tiene una influencia positiva en la curación de diversas lesiones ortopédicas en caballos.
\end{abstract}

Palabras clave: Equino; Laminitis; Células madre mesenquimales.

\title{
1. Introdução
}

O pé do cavalo é uma estrutura complexa que sustenta grande quantidade de peso e força (Pollitt, 2010). Assim, dentre as patologias que acometem o sistema locomotor dos equinos, os cascos e a porção distal do membro torácico são as áreas mais acometidas. Desse modo, a laminite é uma condição grave, bastante estudada e frequentemente compromete o retorno às atividades físicas e à reprodução, e caso não tenha um tratamento adequado pode levar o animal a eutanásia (Laskoski, 2016; Paz, 2019).

$\mathrm{Na}$ laminite ocorre o enfraquecimento da ligação entre o estojo córneo e a falange distal, resultando no afundamento e na rotação palmar/plantar desse osso. Assim, como sua fisiopatologia é parcialmente conhecida, terapias eficazes ainda são escassas (Laskoski, Valadão, Dittrich, Deconto \& Faleiros, 2016; Belknap, 2016). Além disso, o tratamento da laminite pode se tornar longo e complicado e, assim, existe uma urgência para explorar o potencial de novas estratégias preventivas e terapêuticas para animais com tendência de desenvolver essa patologia (Oliveira, 2019).

Nesse contexto, estudos têm mostrado que a terapia celular teve uma influência positiva na cura de várias lesões ortopédicas em equinos (Godwin, Young, Dudhia, Beamish \& Smith, 2008; Lacitignola, Crovace, Rossi \& Francioso, 2008; Oliveira et al., 2011; Dryden \& Morrison., 2013). Ademais, devido às características e funções que as células troncos mesenquimais possuem, seu uso no tratamento de laminite equina é defendido em diversos trabalhos, sendo vista como uma opção terapêutica eficaz para essa enfermidade (Dryden \& Morrison, 2013; Angelone et al., 2017; Yang \& Lopez, 2019). Desse modo, o objetivo deste trabalho é apresentar uma revisão sistemática sobre o potencial terapêutico do uso de célulastroncos mesenquimais na laminite equina.

\section{Metodologia}

Este trabalho se configura como uma revisão de literatura do tipo integrativa, no qual se buscou compilar informações de diversos artigos presentes nas seguintes bases científicas: Scientific Electronic Library Online (SciELO), Google, acadêmico, National Library of Medicine (Pubmed) e ScienceDirect (Souza, Silva \& Carvalho, 2010). Para a busca nestas plataformas, foram selecionadas as seguintes palavras-chave a partir do objetivo desta revisão: "Equino", "Laminite", "Células-tronco mesenquimais”, “Anatomia do casco". Os critérios utilizados para inclusão de determinado material incluíram os artigos originais, em inglês, espanhol e português, bem como livros tidos como referência, que melhor se adequavam ao assunto, e publicados preferencialmente nos últimos 10 anos, porém incluindo também aqueles mais antigos que se enquadraram nos critérios de busca. Foram excluídos artigos incompletos e que não correspondiam à busca. Cada material devidamente selecionado foi analisado, e posteriormente organizado e direcionado para sua utilização no tópico condizente. 


\section{Revisão de Literatura}

\subsection{Anatomia do casco}

A maioria das afecções ortopédicas nos equinos está envolvida com os membros torácicos, sendo 95\% oriunda da parte distal ao carpo, relacionada principalmente com o aparato podotroclear. O motivo pelo qual a maior ocorrência de patologias do sistema locomotor está relacionada a região podotroclear dos membros torácicos deve-se principalmente ao fato desse local suportar entre 60 e $65 \%$ do peso do animal, sendo exposto ao maior impacto contra o solo, o que é reduzido nos membros posteriores, que atuam predominantemente como propulsores (Dyson \& Marks, 2003; Stashak, 2005). Dessa forma, é de extrema importância compreender a anatomia do casco equino para entender melhor o envolvimento de cada estrutura com a patogênese de distúrbios como a laminite (Al-Agele et al., 2019).

A porção do dígito que corresponde o casco é composta pela parte distal da falange média, pela articulação interfalângica distal, pela falange distal, pela cartilagens ungueais lateral e medial, pelo osso sesamóide distal (navicular) com a parte terminal do tendão flexor profundo dos dedos, pela bolsa navicular e pelos vasos sanguíneos e nervos. Ademais, a cápsula do casco é composta por parede, sola, ranilha e bulbo (Budras, 2011; Konig, 2016).

\subsubsection{Segmentos do casco}

A parede é a parte visível quando o cavalo se encontra em posição quadrupedal, é dividida em pinça, quartos e talões e também pode ser subdivida em estrato interno, médio e externo (Budras, 2011; Konig, 2016). Mais detalhadamente, o casco também pode ser disposto em três segmentos, o segmento perióplico ou limbo, o segmento coronário ou coroa e o segmento parietal ou parede (Konig, 2016).

O segmento perióplico circunda o casco na região da pele com pelos, no sentido distal e se alarga no aspecto palmar/plantar onde se funde com a ranilha. A sua derme contém papilas dérmicas curtas, que medem poucos milímetros, onde vão aumentando de comprimento distalmente. A epiderme do limbo compreende o estrato externo da parede do casco. O estrato externo é uma delgada camada córnea tubular, macia e escamosa, que se origina das camadas germinativas da epiderme do períoplo (Thomassian, 2000; Budras, 2011; Konig, 2016).

Distalmente ao segmento perióplico se encontra o segmento coronário, separados por um sulco raso e possui $15 \mathrm{~mm}$ de largura. A derme coronária contém inúmeras papilas, organizadas em fileiras e direcionadas distalmente, onde se tornam mais longas. A epiderme coronária forma o estrato médio da parede do casco (Konig, 2016; Budras, 2011). O estrato médio é a camada mais espessa das três e se caracteriza pela sua estrutura de queratina tubular intertubular. Os túbulos córneos estão orientados paralelamente à superfície externa do casco e suas células queratinizadas abrangem uma organização bastante ordenada. Esse estrato é a principal estrutura de sustentação da parede e serve para transferência da força de reação do solo para o aparato ósseo do cavalo. A sua estrutura anatômica lhe certifica resistência durante a locomoção (Thomassian, 2000; Pollitt, 2010).

Por último, o segmento parietal ou parede forma o estrato interno e está localizado profundamente na parede do casco, expandindo-se do segmento coronário ao solo. A derme parietal encontra-se diretamente na falange distal e na superfície externa das cartilagens do casco, e compõe-se de lâminas primárias e secundárias orientadas proximodistalmente. Além disso, contém papilas na crista na sua porção proximal e distal. Já a epiderme desse segmento, similarmente a derme, contém lamelas primárias e secundárias que se entrelaçam com as lâminas dérmicas, formando as lamelas córneas (Budras, 2011; Konig, 2016). 


\subsubsection{Articulação e ligamentos do casco}

A articulação contida no casco é a articulação interfalângica distal, ela é considerada uma articulação complexa porque envolve o osso sesamóide distal, a falange média e a falange distal. Cada osso articula-se com os outros dois, contudo existe pouco movimento entre a falange distal e o osso navicular. As articulações interfalângicas são classificadas como selares, em que as superfícies são reciprocamente côncavo-convexa, pois além da flexão e extensão elas conseguem realizar pequeno movimento lateral, como discreta rotação (Parks, 2003).

Existe um grande número de ligamentos no membro distal, que mantém as articulações em posição e guia seus movimentos, principalmente pelo fato de não existir nenhum outro tecido volumoso, como músculos, na extremidade distal para fornecer estabilidade. Desse modo, a estabilidade desta articulação é promovida por dois ligamentos colaterais, curtos e espessos, pelo ligamento sesamóide colateral, pelo ligamento sesamóide distal ímpar e pela cápsula articular. O osso navicular, que faz parte da articulação, fica suspenso a partir da extremidade distal da falange proximal pelos ligamentos colaterais naviculares. Os ligamentos colaterais naviculares cruzam as margens medial e lateral da falange média e fixam-se na região proximal do navicular. Ademais, o ligamento sesamóide distal muito curto e largo une a margem distal do osso com a falange distal, ancorando-se proximal aos proeminentes forames da sola. A cápsula adere às margens articulares dos três ossos e possuem recessos dorsal e palmar e as bolsas sinoviais da cápsula articular estão presentes no aspecto palmar e/ou plantar da articulação dorsal e abaxial ao tendão flexor digital profundo e axial as cartilagens colaterais da falange distal (Céleste \& Szöke, 2005; Dyce, 2010).

\subsubsection{Tendões do casco}

Os tendões de inserção dos dois músculos extensores e dos dois músculos flexores do dedo, que são o tendão flexor digital superficial (TFDS), tendão flexor digital profundo (TFDF), tendão extensor digital lateral (TEDL) e tendão extensor digital comum (TEDC), respectivamente, ligam-se aos ossos presentes na extremidade distal do membro. O TEDL se insere na face próximo-lateral da falange proximal. O TEDC se insere principalmente no processo extensor da falange distal, mas também na superfície dorsal da falange média. Proximal à articulação metacarpofalangiana, o TFDS forma um túnel através do qual o TFDP passa enquanto ambos os tendões percorrem a superfície flexora da articulação metacarpofalangiana. $\mathrm{Na}$ extremidade distal da falange proximal, o TFDS bifurca-se em duas partes que se inserem principalmente na face proximal palmar da falange média, com inserção secundária menor na face distal palmar da falange proximal. Depois de passar sobre as superfícies flexoras dos sesamoides proximais dentro do túnel formado pelo TFDS, o TFDP se dirige palmamente para os ligamentos sesamoides distais e sobre a superfície flexora do sesamoide distal para inserir na superfície flexora do falange distal. Ambos os tendões flexores compartilham uma bainha de tendão flexor digital comum que se estende do metacarpo distal proximalmente perto da bursa navicular distalmente (Parks, 2003).

\subsubsection{Vascularização e inervação do casco}

O suprimento vascular para o casco é obtido através do par de vasos digitais palmares ou plantares (artérias e veias). As artérias digitais palmares/plantares lateral e medial, que são ramos da artéria digital palmar comum e da artéria metatarsal dorsal III respectivamente. No membro pélvico, as artérias digitais plantares comuns menores II e III também colaboram para a formação das artérias digitais (Konig, 2016).

Na superfície palmar da falange distal, contém ramos pareados da artéria digital palmar que se estendem distalmente aos bulbos do calcanhar e almofada digital. Os ramos para os coxins dos calcanhares e as artérias coronárias medial e lateral se desprendem na altura da falange média. Após enviar ramos para a cunha e para as diferentes partes da parede do casco, essas artérias entram a falange distal nas faces medial e lateral e se anastomosam no interior do osso para formar o arco terminal. A 
partir deste arco terminal, inúmeros vasos perfuram a superfície parietal da falange distal com o intuito de suprir os tecidos moles não queratinizados sobrejacentes no interior da cápsula do casco (Konig, 2016; Belknap, 2016).

A drenagem do sangue através das veias é complexa e semelhante ao suprimento arterial (Parks, 2003). A principal diferença é a presença de três plexos venosos, o plexo venoso dorsal, na região profunda da derme lamelar, o plexo venoso palmar/plantar, na região profunda na derme e superfície interna axial das cartilagens ungueais e o plexo coronário, no coxim coronário, se estendendo até o tendão extensor digital e a superfície externa abaxial da cartilagem da falange distal. Esses plexos são drenados pelas veias digitais lateral e medial (Pollitt, 2004).

No membro torácico, a inervação sensorial do casco é promovida pelos ramos do nervo mediano. Os nervos digitais palmares comuns II e III seguem como nervos digitais palmares lateral e medial após emitirem um ramo dorsal para os segmentos perióplico, coronário e parietal. Os coxins do casco, a articulação interfalângica distal e o complexo navicular recebem ramos dos nervos digitais palmares. Ademais, estes nervos inervam a parte palmar das cartilagens do casco, a parede, a sola, a cunha e os coxins do casco (Konig, 2016).

Já a inervação do membro pélvico ocorre pelos nervos digitais comuns II e III, que são ramos do nervo tibial. Seu padrão de ramificação é semelhante ao dos nervos correspondentes do membro torácico. O dedo do casco recebe inervação adicional por nervos metatarsais dorsais lateral e medial, ramos do nervo fibular profundo (Konig, 2016).

\subsection{Fisiopatologia da laminite}

Estudos divergem constantemente quanto a etiologia, fisiopatologia e tratamento da laminite em equinos. Nesse sentido, apesar de apresentar uma casuística elevada dentro da rotina da clínica médica de equinos, os esclarecimentos acerca da patologia, infelizmente, ainda são escassos quando comparados com a sua demanda (Mitchell, Fugler \& Eades, 2015; Baker, 2012).

As principais teorias que explicam sua fisiopatologia são a vascular, a traumática, a enzimática, a de privação de glicose e a endocrinopática. A teoria vascular, que também pode ser chamada de isquêmica, defende que a alteração da perfusão digital, por venoconstrição, é a responsável pelo desenvolvimento da disfunção metabólica e falha estrutural das lâminas do casco. O mediador que provoca essas alterações vasculares ainda não foi determinado, mas estudos apontam para um desequilíbrio na libertação/regulação da endotelina-1 e do óxido nítrico (regulador da liberação da endotelina-1) (Reis, 2015). Segundo Stokes (2004), o aumento da venoconstrição resulta num aumento da resistência vascular bem como um aumento da pressão hidrostática capilar, o que força a saída do líquido intersticial dos capilares para o interstício, aumentando a pressão intersticial, quando essa pressão é excessiva, os capilares colapsam, o que leva à diminuição do suprimento vascular arterial. Nesse sentido, a pressão aumentada num espaço anatômico confinado afeta a circulação sanguínea nesses tecidos, podendo levar a isquemia, sendo esta condição referida como síndrome de compartimentalização. Após um período prolongado de isquemia, as lâminas entram em necrose, levando à separação das lâminas dérmicas e epidérmicas e consequente afundamento e/ou rotação da falange distal.

Na traumática ou mecânica, a ocorrência da laminite é atribuída a um trauma direto no casco e não a alguma causa sistêmica. Segundo Busch (2009), a força mecânica exercida no tecido, impacto excessivo em pisos muito duros, caminhadas longas ou por apoio excessivo no membro quando o contralateral padece de claudicação severa (quando não é capaz de suportar qualquer peso), seriam capazes de causar uma reação inflamatória, gerando um aumento da pressão local, levando à formação de edema e à abertura de anastomoses arteriovenosas que prejudicam ainda mais a circulação nos tecidos laminares, causando isquemia e necrose tecidual e, assim como na teoria vascular, ocorrendo o afrouxamento das lâminas que podem causar a rotação ou afundamento da terceira falange. 
A hipótese enzimática explica que a presença de endotoxinas, provenientes de outros processos patológicos ocorridos no organismo, resulta na ativação da produção de metaloproteinases (MMPs) que desencadearia todo o processo de resposta inflamatória (Busch, 2009). Ela defende que essa ativação e liberação das MMPs têm um papel importante na separação das células das lâminas da membrana basal e na separação das lâminas dérmicas e epidérmicas (Pollitt, 2007).

Já a teoria de privação de glicose afirma que tais processos patológicos causam um estresse responsável pelo consumo excessivo de glicose, que seria direcionada para órgãos vitais, como o cérebro e o coração. Essa diminuição da glicose e a produção de cortisol seriam responsáveis pela ativação da produção de metaloproteinases, desencadeando todo o processo (Busch, 2009).

Por fim, a laminite endócrina refere-se à laminite que ocorre a partir de uma suposta disfunção hormonal, em vez de ocorrer em associação com condições pró-inflamatórias ou intestinais (Johnson et al., 2004). Nesse sentido, ela tem sido associada à síndrome metabólica equina (SME), à resistência à insulina (RI), à síndrome de Cushing (disfunção da pars intermedia da glândula pituitária - DPIP) ou à iatrogenia pela administração de corticóides exógenos (Paz, 2019). De acordo com Paz (2019), é possível que o desarranjo entre glicose e insulina possa estar relacionado às alterações pró-inflamatórias e efeitos sobre os capilares em pacientes portadores de RI. A disfunção vascular manifesta-se como vasoconstrição e atividade pró-coagulante que, cronicamente, envolve remodelamento vascular.

\subsection{Evolução e sinais clínicos da laminite}

Progressivamente, a laminite equina pode ser dividida em três estágios: fase de desenvolvimento, fase aguda, subaguda e crônica. A fase de desenvolvimento precede o aparecimento de claudicação e se caracteriza pela presença de uma doença prévia ou fator predisponente cuja sucessão pode desencadear a lesão laminar, de modo que uma intervenção clínica nesse momento é capaz de prevenir o desenvolvimento da laminite e melhorar o prognóstico (Baker, 2012).

Após a lesão do tecido laminar, o equino apresenta os primeiros sinais relacionados à claudicação, marcando o início da fase aguda. $\mathrm{O}$ animal tende a deslocar seu peso dependendo dos membros acometidos, isto é, sendo esses os membros anteriores, o peso será desviado para os posteriores. Sendo um único membro afetado, o desvio ocorre para o membro contralateral. De maneira frequente, a laminite afeta os membros anteriores, tendo em vista que são eles que suportam, aproximadamente, $65 \%$ do peso do equino. Ainda na fase aguda, o casco apresenta calor e as artérias digitais sobre o boleto apresentam pulso saliente sendo ambos palpáveis. Também ocorre aumento da frequência cardíaca e respiratória, da pressão sanguínea, além dos animais poderem sofrer tremores e apresentarem sudorese e angústia (Pollitt, 2008).

Além disso, iniciado o tratamento, tanto da doença primária como da laminite, há uma grande chance de a progressão da doença se manifestar de forma subaguda (fase subaguda) na qual existe indícios clínicos de laminite por, aproximadamente, 72 horas, mas não ocorreu o deslocamento da falange distal, comprovado por exames radiográficos (Hood, 1999).

Posteriormente, ocorrendo a persistência da lesão laminar e, consequentemente, da dor, é iniciada a fase crônica, sendo definida pelo deslocamento da falange distal (rotação ou afundamento) ou pelo período superior a 72 horas de dor no casco. Nessa fase, há dor severa contínua, claudicação crônica, decúbito, caimento da sola advindo da perfuração pela falange distal, crescimento deformado do casco e formação de anéis na parede do casco (Pollitt, 2004; Pollitt, 2008; Morrison, 2010).

\subsection{Diagnóstico}

A presença de sinais clínicos correspondentes à doença como a existência de postura característica e a realização de exame físico como a palpação das artérias digitais juntamente ao histórico do animal, é o diagnóstico lógico a ser seguido no caso da laminite em fase aguda (Ferreira, 2008; Baker, 2012). No caso da fase crônica, há uma maior dificuldade na realização do diagnóstico pelos sinais clínicos, principalmente em animais idosos cujo sistema locomotor já foi afetado anteriormente. 
Dessa forma, é importante ressaltar a necessidade da utilização da radiografia tanto para o monitoramento da doença, sendo um valioso auxílio na sucessão do quadro e do tratamento, quanto para um diagnóstico preciso nos casos de laminite crônica (Parks \& O'Grady, 2003). As projeções mais importantes a serem realizadas são as lateromediais e as dorsopalmares ou dorsoplantares (Fürst \& Lischer, 2006; Hunt \& Wharton, 2010).

Além disso, outro modo de diagnosticar a laminite é através da execução de bloqueios anestésicos cujos resultados devem ser analisados considerando o histórico, sinais clínicos e radiografias a fim de evitar um diagnóstico errôneo. Em geral, nos casos de laminite crônica severa, o membro pode não cessar a claudicação por completo em resposta ao bloqueio local, indicando a existência de disfunção na parte superior do membro (Reis, 2014; Belknap, Parks \& Dern, 2020).

Outra técnica utilizada, que define primariamente o prognóstico do animal, é a venografia. A venografia é capaz de diagnosticar uma condição de má perfusão sanguínea demonstrando problemas no enchimento venoso resultantes da patologia progressiva ocorrida na parede do casco e da sola (Pollitt, 2008; Reis, 2014).

A literatura também relata a termografia como uma possibilidade para o diagnóstico e monitoramento em casos de laminite sendo um método não invasivo, rápido e preciso. Esse exame é eficaz principalmente nos estágios iniciais da doença (fase aguda) em que é possível detectar uma mudança no padrão de temperatura da parede do casco decorrente do intenso processo inflamatório (Redaelli et al., 2017). Assim, é importante ressaltar o uso da termografia em complementaridade ao exame físico e à radiografia na detecção precoce desta enfermidade através de informações adicionais relevantes para o prognóstico da doença (Turner, 2020).

\subsection{Tratamento}

Em relação ao tratamento, deve-se tratar a doença primária ou o fator desencadeador que gera a laminite. Antes do aparecimento de desconforto no casco, estando o animal em risco de desenvolver a doença, estudos demonstram os benefícios da crioterapia em proteger o tecido laminar de lesões de forma preventiva (Van Eps, 2010; Van Eps, Walters, Baldwin, McGarry, \& Pollitt, 2004). Kullmann et al. (2014) corroboraram essa estratégia demonstrando em seu estudo que cavalos que foram submetidos a crioterapia apresentaram dez vezes menos chances de desenvolverem laminite associada à sepse quando comparados aos animais que não utilizaram essa terapia.

Com a finalidade de promover suporte à dor e estabilização do tecido laminar, o tratamento preconizado envolve a combinação de tratamento terapêutico, tratamento suporte e tratamento cirúrgico. O uso de anti-inflamatórios não esteroidais (AINES) é o centro da terapêutica relacionada à laminite (Driessen, Bauquier, Zarucco, 2010). Além de diminuírem os efeitos da inflamação antes do início e no início da doença, apresentam efeitos analgésicos precisos. É importante ressaltar os efeitos tóxicos causados por esses medicamentos no sistema gastrointestinal e no sistema renal, gerando a necessidade de monitoramento frequente do nível de hidratação e da realização de exames laboratoriais para acompanhamento dos parâmetros renais (Belknap et al., 2020).

Os quatro principais AINES utilizados são: flunixin meglumine, fenilbutazona, cetoprofeno e meloxicam, esse sendo ciclo-oxigenase-2 (COX-2) seletivo e aqueles não seletivos (Carvalho, 2019). A fenilbutazona é a droga mais comumente usada e eficaz no manejo da dor em cavalos com laminite, sendo que a administração simultânea ao flunixin meglumine não promove uma melhor analgesia e pode aumentar a incidência de efeitos colaterais (Sanchez \& Robertson, 2014). O Meloxicam pode ser uma alternativa de utilização considerando que ele apresenta uma maior seletividade a COX-2 e, consequentemente, uma menor chance de causar acidentes vasculares, além de possuir pouca incidência de efeitos colaterais, porém sua eficácia no controle da dor é questionável (Mitchell et al., 2015; Belknap et al., 2020).

O flunixin meglumine apresenta alta eficácia contra a endotoxemia e é indicado em quadros em que o animal não possui desidratação ou problemas renais. Já o cetoprofeno é utilizado quando há comprometimento renal melhorando tanto o 
quadro de claudicação como o endotoxêmico. A ação analgésica é realizada principalmente pela administração de fenilbutazona, no entanto, ela gera uma toxicidade maior quando comparada aos outros AINES (Belknap et al., 2020).

Além do uso de AINES, também há a utilização de drogas para aumentar o aporte de fluxo sanguíneo no tecido laminar. Estudos indicam que a droga mais eficaz que permite esse aumento, por meio da vasodilatação, é a acepromazina, devido à sua ação antagonista alfa-1. Apesar de ser comumente usada no tratamento dessa enfermidade, alguns estudos recentes refutam essa condição demonstrando a não eficácia dessa droga no aumento do fluxo sanguíneo laminar (Bailey \& Eades, 2017). Driessen et al. (2010) propuseram a associação de opioide, como metadona, morfina e butorfanol, aos agonistas alfa-2 e à acepromazina para gerar um quadro de antinocicepção ou analgesia.

Além desses medicamentos, o ferrageamento terapêutico é de extrema importância na tentativa de gerar estabilização do casco sem o progresso da lesão laminar. A escolha da ferradura é de preferência do clínico e deve ser escolhida levando em consideração o custo, disponibilidade e como ela vai influenciar na dinâmica do casco a partir dos princípios de cada modelo de ferradura. O tempo estimado de utilização é variável e depende da severidade e recorrência da doença como também se há o desenvolvimento de complicações. Equinos que possuem um alto índice de recorrência ou desenvolvem complicações, demoram mais a retirar a ferradura e podem não ter uma melhora significativa. Nesses casos em que a estabilização não foi alcançada, pode-se recorrer ao tratamento cirúrgico sendo eles: tenotomia do tendão flexor digital profundo, ressecção da parede do casco e realização de um sulco coronário (Pollitt, 2008; Baker, 2012; Belknap et al., 2020).

Estudos recentes têm apresentado a possibilidade de uso da ozonioterapia na fase crônica da laminite, em vista de sua ação antioxidante, além de atuar no manejo da dor (Coelho et al., 2015; Colin \& Amaro, 2019). A medicina regenerativa tem sido proposta como uma alternativa viável para tratamento de diversas afecções do sistema locomotor em equinos, como o soro condicionado autólogo, a solução de proteína autóloga, a terapia com células-tronco e o plasma rico em plaquetas (PRP) (Ribitsch, Oreff \& Jenner, 2021). Carmona et al. (2017) relataram casos bem sucedidos de equinos com laminite crônica tratados com PRP. Schnabel et al. (2013) citam a possibilidade de utilização de células-tronco mesenquimais em diversas patologias osteoarticulares equinos, como tendinite, desmite do ligamento suspensório do boleto, incluindo em quadros agudos da laminite, a fim de reduzir o processo inflamatório, contudo mais estudos são necessários para avaliar a eficácia e a segurança das células-tronco no tratamento da laminite (Mitchell et al., 2015).

\subsection{Células-tronco: uma visão geral}

Células-tronco podem ser definidas como células indiferenciadas e não-especializadas, as quais possuem características intrínsecas, que as diferenciam das demais populações celulares. Possuem ampla capacidade de autorrenovação, ou seja, podem-se multiplicar por meio de mitoses assimétricas e manter-se indiferenciada, e de gerarem diferentes tipos celulares, reconstruindo tipo tecidual específico (Zago \& Covas, 2004; Morrison, Shah \& Anderson,1997).

Pode-se citar dois grupos de células-tronco baseados em sua origem, as células-tronco adultas (CTA) e as célulastronco embrionárias (CTE). As CTE são derivadas de células que fazem parte de um embrião inicial, de 4 a 5 dias, chamado blastocisto. Uma vez removidas as células internas desse estágio embrionário, pode-se realizar o cultivo em CTE. O blastocisto é capaz de originar todos os órgãos do organismo, de forma que as CTE apresentam grande plasticidade, sendo, assim, classificadas como pluripotentes e totipotentes, propriedade de gerar qualquer tipo celular, incluindo os três anexos fetais (ectoderma, mesoderma e endorderma). Embora as CTE possuam um grande potencial terapêutico, há um grande obstáculo ético envolvido na destruição de embriões para se trabalhar com essas células. Além disso, as CTE apresentam grande imunorreatividade e elevado potencial teratogênico, características envolvidas com a rejeição do hospedeiro e com a formação de tumores embrionários, respectivamente (Kirschstein \& Skirboll, 2001; Pranke, 2004; Zago \& Covas, 2004). 
Já as CTA ou somáticas são células indiferenciadas presentes em tecidos adultos ou diferenciados, que podem ser obtidas do sangue periférico, córnea e retina do olho, cérebro, músculo esquelético, polpa dentária, fígado, pele, revestimento do trato gastrointestinal, pâncreas e cordão umbilical, sendo as da medula óssea as mais estudadas (Kirschstein \& Skirboll, 2001). Seu papel em um organismo vivo é manter e reparar o tecido em que se encontram (Del Carlo, 2005). Em oposição às CTE, apresentam menores concentrações de telomerase, enzima que restaura os telômeros, parte final do DNA, que controla o número de vezes que a célula pode se dividir, fator limitante da capacidade de autorrenovação (Verfaillie, Pera \& Lansdorp, 2002). Existem dois tipos principais de CTA, as células-tronco hematopoiéticas (CTH), capazes de se diferenciar nas linhagens sanguíneas e imunes (Kirschstein \& Skirboll, 2001) e as células-tronco mesenquimais ou estromais (CTM), de caráter multipotente, derivadas do mesoderma embrionário, responsáveis pela formação dos tecidos ósseo, cartilaginoso e adiposo (Singer \& Caplan, 2011).

O uso de células-tronco mesenquimais tem sido defendido como alternativa de tratamento de doenças osteomusculares nos equinos. Os locais mais comuns para obtenção dessas células são a medula óssea e o tecido adiposo. Nos equinos, a colheita de medula óssea é, normalmente, realizada do esterno ou da tuberosidade do íleo, enquanto do tecido adiposo é colhido da região subcutânea da base da cauda. Posteriormente, a amostra deve ser encaminhada a um laboratório para separação da fração mononuclear (medula óssea) ou estromal (tecido adiposo) e para a cultura celular (Goodrich, Frisbie \& Kisiday, 2008; Alvarenga, 2019). Nos estudos realizados por Koch, Heerkens, Thomsen \& Betts (2007), permitiu-se demonstrar a possibilidade de obtenção de CTM a partir do sangue fresco do cordão umbilical de potros imediatamente após o parto. Ademais, as CTM podem advir do próprio animal (autótolo) ou de animal doador (alogênico), no entanto o potencial proliferativo reduz com a idade, o que limita a utilização de CTM autólogas em animais idosos (Dhingra, Huang \& Li, 2010).

Embora não se saiba ao exato os mecanismos que regem as células-tronco mesenquimais, pode-se afirmar que estas secretam moléculas bioativas de caráter imunomodulatório, sendo capazes de suprimir o reconhecimento imunológico e/ou a expansão de células B e T, além de possuírem atividades regenerativas e de fornecerem um microambiente adequado para a sobrevida a longo prazo das células-tronco hematopoéticas. Os agentes bioativos secretados possuem efeitos autócrinos e parácrinos, e medeiam as respostas funcionais dos tecidos, uma vez que demonstraram ser capazes de inibir a cicatrização tecidual e a apoptose, promover a angiogênese e estimular vias de regeneração neurológicas funcionais, com ganho de sua função, sendo essa função secretória referida como "atividade trófica" (Caplan \& Dennis,2006; Nöth, Rackwitz, Steinert, \& Tuan, 2010).

\subsection{Efeitos da terapia com células tronco mesenquimais na laminite}

Partindo da premissa de que na laminite equina há intenso processo inflamatório laminar, com alteração na dinâmica vascular e dano isquêmico, pode-se evidenciar o papel protetor promovido pelas CTM, as quais apresentam atividade antiinflamatória, ação antioxidante, prevenindo os danos causados pela hipóxia, além de promoverem a angiogênese e preservarem a integridade endotelial (Prockop \& Oh, 2012; GU et al., 2016; Inan et al., 2017; Angelone et al., 2017).

A perfusão regional de CTM nos membros de equinos com laminite pode ser feita por meio da veia distal lateral ao nível do osso sesamóide. Além disso, os cavalos devem ser tratados na fase aguda da doença, a fim de reduzir a resposta inflamatória, o que requer CTM alogênicas ou banco de CTM autólogas. A terapia com células-tronco mesenquimais, na maioria das vezes, é realizada duas vezes, a primeira sendo realizada próximo ao episódio agudo e a segunda, 14 dias após a primeira aplicação (Schnabel, Fortier, Mcllwrait, \& Nobert, 2013).

Angelone et al. (2017) sugeriram a associação do plasma rico em plaquetas com as CTM derivadas do tecido adiposo no tratamento da laminite equina, obtendo a melhora da aparência macroscópica do casco e evidenciando, por meio de venografia, a recuperação progressiva da vascularização do casco, levando à restauração da rede vascular. Esses resultados 
comprovam o potencial de CTM como terapêutica para laminite, patologia em que a circulação venosa ou arterial está comprometida, além de permitirem observar que as CTM controlam a inflamação, reduzem os efeitos negativos promovidos pelas espécies reativas de oxigênio e promovem a homeostase tecidual. O plasma rico em plaquetas reforça as propriedades biológicas das CTM, devido aos fatores bioativos presentes nas plaquetas, assim como, estimula a proliferação de célulastronco indiferenciadas e a diferenciação celular, promovendo a regeneração tecidual (Tobita, Tajima \& Mizuno, 2005; Angelone et al., 2017).

\section{Considerações Finais}

A laminite é uma enfermidade bastante recorrente na rotina clínica de equinos, sendo considerada uma doença complexa, desafiadora e de relevância significativa. Dessa forma, trabalhos que utilizaram a terapia celular no tratamento de equídeos com laminite, demonstraram resultados bastante promissores. Podemos concluir que esse instrumento terapêutico pode ser um grande aliado no tratamento de laminite, tanto na fase aguda quanto na crônica, porém são necessários mais estudos para possibilitar um melhor entendimento acerca do seu mecanismo de ação e do potencial terapêutico.

\section{Referências}

Al-Agele, R.; Paul, E.; Kubale, V.; Craig J.; Sturrock, C. R.; Rauch, C.; Rutland, C. S. (2019). The Anatomy, Histology and Physiology of the Healthy and Lame Equine Hoof. In: Rutland, C. Veterinary Anatomy and Physiology (p. 1934-1952). Nottingham, Inglaterra: Intechopen.

Alvarenga, M.L. (2019). Células-tronco: do básico ao aplicado. Revista Equina, 83 (1), 36-37.

Angelone, M; Coli, V.; Biacca, C.; Battaglia, B.; Pecorali, L.; Piana, F. Gnudi,,G.; Leonardi, F.; Ramoni, R.; Basini, G.; Dotti,S.; Renzi,S.; Ferrari, M.; Grolli, S. (2017). The Contribution of Adipose Tissue-Derived Mesenchymal Stem Cells and Platelet-Rich Plasma to the Treatment of Chronic Equine Laminitis: A Proof of Concept. International Journal of Molecular Science, 18 (10), 2022.

Bailey, S.R. \& Eades, S.C. (2017). Vasoactive Drug Therapy. In: J.K. Belknap, R. J. Geor. Equine Laminitis (1ª ed., pp. 284-290). Hoboken, EUA: WileyBlackwell.

Baker, W. R. (2012). Treating Laminitis. Veterinary Clinics of North America: Equine Practice, 28 (2), 441-455.

Belknap, J.K (2016). Equine Laminitis (1ºd) . Nova Jersey: Wiley Blackwell.

Belknap, J.; Parks, A. \& Dern, K. (2020). Lameness of the Distal Limb. In: G. M. Baxter. Adams and Stashak's Lameness in Horses (7 a ed, pp. 490-511). Hoboken, EUA: Wiley-Blackwell.

Budras, K.D., Sack, W.O. \& Rock, S. (2012). Anatomy of the horse (6º ed), Hannover, Alemanha: Schlütersche.

Busch, L. (2009). Atualidades no tratamento da laminite em equinos. Trabalho de Conclusão de curso (Graduação em Medicina Veterinária). Universidade Júlio Mesquita Filho, Botucatu, Brasil.

Caplan, A.I. \& Dennis, J.E. (2006). Mesenchymal stem cells as trophic mediators. Journal of Cellular Biochemistry, 98(5), 1076-1085.

Carmona, J.; Gómez, W. \& López, C. (2017). Could platelet-rich plasma be a clinical treatment for horses with laminitis?. Journal of Equine Veterinary Science, 61, 46-57.

Céleste, C. J. \& Szöke, M. O. (2005). Management of Equine Hoof Injuries. Veterinary Clinical Equine, 21 (1), 167-190.

Coelho, C.; Bernardi, W.; Ginelli, A.; Spagnol,T.; Gardel, L.; Souza, V. (2015). Use of ozone therapy in chronic laminitis in a horse. Journal of ozone therapy, $1(1), 1-7$.

Colin, E. \& Amaro, S. (2019). Ozone Therapy for equine laminitis. Journal of Ozone Therapy, 3(4), 16-17.

Carvalho, B. V. L. (2019). Tratamento para Laminite Equina: uma revisão sistemática (Monografia). Universidade Federal Rural da Amazônia, Pará, Brasil.

Del Carlo, R.J. (2005). Células-tronco: células da esperança. Revista CFMV, 1 (35), 60-68.

Dhingra, S.; Huang, X. \& Li, R. (2010). Challenges in allogeneic mesenchymal stem cellmediated cardiac repair. Trends Cardiovasc Med, 20 (8), $263-268$.

Dyce, K. M. (2010). Tratado de anatomia veterinária (4ºd). Rio de Janeiro, RJ:Guanabara Koogan.

Dyson, S. \& Marks, D. (2003). Foot pain and the elusive diagnosis. Vet. Clin. N. Am. Equine Pract., 19 (2),.531-565.

Dryden, V.C. \& Morrison, S. (2013). Using stem cells in clinical cases. Journal of Equine Veterinary Science, 33 (10), $872-873$. 
Driessen, B.; Bauquier, S. H. \& Zarucco, L. (2010). Neuropathic pain management in chronic laminitis. Veterinary Clinics of North America - Equine Practice, 26 (2), 315-337.

Ferreira, C. R. L. V. (2008). Laminites em eqüinos (Dissertação de Mestrado). Universidade de Lisboa, Lisboa, Portugal.

Fürst, A.E \& Lischer, C.J. (2006). Foot. In: A. J. Auer, J. A. Stick (3 ${ }^{a}$ ed), Equine Surgery (p. 1184-1217). St. Louis, EUA: Saunders.

Goodrich, L.R., Frisbie, D.D. \& Kisiday, J.D. (2008). How to harvest bone marrow derived mesenchymal stem cells for expansion and injection. Proc. American Association Equine Practioners, 54, 253-257.

Godwin, E.E., Young, N.J., Dudhia, J., Beamish, I.C. \& Smith, R.K. (2012). Implantation of bone marrow-derived mesenchymal stem cells demonstrates improved outcome in horses with overstrain injury of the superficial digital flexor tendon. Equine Vet. J., (44), 25-32.

Gu, W., Hong, X., Potter, C., Qu, A. \& Xu, Q. (2016). Mesenchymal Stem Cells and Vascular Regeneration. Microcirculation, 24(1), 1-31.

Inan, M., Bakar, E., Cerkezkayabekir, A., Sanal, F., Ulucam, E., Subasi, C., Karaöz, E. (2017). Mesenchymal stem cells increase antioxidant capacity in intestinal ischemia/reperfusion damage. Journal Pediatric Surgery, 52 (7), 1196-1206.

Hood, D.M. (1999). Laminitis in the Horse. Veterinary Clinical of North American Association of Equine Practice, 15 (2), $287-294$.

Hunt, R.J. \& Wharton, R.E. (2010). Clinical Presentation, Diagnosis, and Prognosis of Chronic Laminitis in North America. Veterinary Clinical of North American Association of Equine Practice, 26 (1), 141-153.

Johnson, P.J.; Messer, N.T.; Slight, S.H.; Wiedmeyer, C; Preston, C.G.; Venkataseshu, B. (2004). Endocrinopathic laminitis in the horse. Cli. Tech. Eq. Pract., $3(1), 45-56$.

Kirschstein, R. \& Skirboll, L. (2001). Stem Cells: Scientific Progress and Future Research Directions. Washington, EUA: Terese Winslow.

König, H.E. \& Liebich, H. G. (2016). Anatomia dos animais domésticos: texto e atlas colorido (6ª ed, 824 p). Porto Alegre, Brasil: Artmed.

Koch, T.G., Heerkens, T., Thomsen, P.D. \& Betts, D.H. (2007). Isolation of mesenchymal stem cells from equine umbilical cord blood. BMC Biotechnology, 7 (1), 26 .

Kullmann, A.; Holcombe, S. J.; Hurcombe, S. D.; Roessner, H. A.; Hauptman, J. G.; Geor, R. J.; Belknap, J. (2014). Prophylactic digital cryotherapy is associated with decreased incidence of laminitis in horses diagnosed with colitis. Equine Veterinary Journal, 46 (5), 554-559.

Lacitignola, L.; Crovace, A.; Rossi, G. \& Francioso, E. (2008). Cell therapy for tendinitis, experimental and clinical report. Vet Res Commun, (32), 33-8.

Laskoski, L. M.; Valadão, C. A. A.; Dittrich, R. L.; Deconto, I. \& Faleiros, R. R. (2016). An update on equine laminitis. Ciência Rural, (46), 547-553.

Mitchell, C.; Fugler, L. \& Eades, S. (2015). The management of equine acute laminitis. Veterinary Medicine: Research and Reports, 6, 39-47.

Morrison, S. (2010). Chronic laminitis: Foot management. Veterinary Clinics of North America: Equine Practice, 26 (2), $425-446$.

Morrison, S.J.; Shah, N.M. \& Anderson, D.J. (1997). Regulatory mechanisms in stem cell biology. Cell, 88, $287-298$.

Nöth, U.; Rackwitz, L.; Steinert, A.F. \& Tuan, R.S. (2010). Cell delivery therapeutics for musculoskeletal regeneration. Advanced Drug Delivery Reviews, 62(7-8), 765-783.

Oliveira, P.G.G.; Alves, A.L.G.; Carvalho, A.M.; Hussni, C.A.; Watanabe, M.J.; Amorim, R.L.; Rodrigues, M.M.P.; Mota, L.S. (2011). Uso de células mononucleares da medula óssea no tratamento de tendinites induzidas experimentalmente em equinos. Arq. Bras. Med. Vet. Zootec., 63 (6), 1391-1398.

Oliveira, A.P.L. (2019). Células tronco mesenquimais autólogas infundidas por perfusão regional venosa na terapia da laminite crônica em equinos (Tese de doutorado). Universidade Federal de Minas Gerais, BH, Brasil.

Parks, A. (2003). Form and function of the equine digit. The Veterinary Clinics: Equine Practice, 19 (2), 285-307.

Parks, A. \& O'Grady, S.E (2003). Chronic laminitis: current treatment strategies.Vet Clin North Am Equine Pract, 19 (2), $393-416$.

Paz, C. F. R. (2019). Cinemática de equinos hígidos, com laminite crônica ou com claudicação induzida portando diferentes órteses podais (Tese de doutorado). Universidade Federal de Minas Gerais, Belo Horizonte, Brasil.

Pollitt, C.C. (2004). Anatomy and physiology of the inner hoof wall. Clinical Techniques in Equine Practice, 3 (1), 3-21.

Pollitt, C.C. (2008). Equine laminitis: current concepts (pp. 116). Missouri: Rural Industries Research and Development Corporation.

Pollitt, C.C. (2007). Update on the pathophysiology of laminitis. Proceedings of the 10th Geneva Congress of Equine Medicine, Colorado, EUA.

Pollitt, C.C. (2010). The Anatomy and Physiology of the Suspensory Apparatus of the Distal Phalanx. Veterinary Clinics of North America: Equine Practice, $26(1), 29-49$.

Pranke, P. (2004). A importância de discutir o uso de células-tronco embrionárias para fins terapêuticos. Ciência e Cultura, 56 (3), 33 -38.

Prockop, D.J. \& Oh, J.Y. (2012). Mesenchymal stem/stromal cells (MSCs): Role as guardians of inflammation. The American Society of Gene \& Cell Therapy, 20(1), 14-20. 
Redaelli, V.; Valle, E.; Solimeno, C.; Cozzi, M.C.; Aarrigoni, A.; Luzi, F.; Bergero, D. (2017). Utilizzo della tecnica termográfica per il rilevamento dela temperatura della corona come fattore di rischio per la laminite nel cavalo Uno studio preliminare. Veterinaria Pratica Equina, 2 (2), 1-5.

Reis, F. B. (2014). Laminite em equinos (Trabalho de Conclusão de curso). Universidade Federal do Rio Grande do Sul, Porto Alegre, Brasil.

Ribitsch, I.; Oreff, G. \& Jenner, F. (2021). Regenerative medicine for equine musculoskeletal diseases. Animals, 11(1), 1-30.

Sanchez, L. C. \& Robertson, S. (2014) A. Pain control in horses: What do we really know?. Equine Veterinary Journal, 46 (4), $517-523$.

Schanabel, L.V., Fortier, L.A; Mcllwrait, C.W \& Nobert, K.M. (2013). Therapeutic use of stem cells in horses:Which type, how, and when?. The Veterinary Journal, 197(3), 570-577.

Singer, N.G. \& Caplan, A.I. (2001). Mesenchymal stem cells: mechanisms of inflammation. The Annual Review of Pathology: Mechanisms of Disease, 6(1), 457- 478

Souza, M.T; Silva, M. D. \& Carvalho, R. (2010). Revisão integrativa: o que é e como fazer?. Einstein, 8(1), $103-106$.

Stashak, T.S. (2005). Claudicação em equinos segundo Adams (5 ed). São Paulo, SP: Roca.

Stokes, A.M., Eades, S.C. \& Moore, R.M. (2004). Pathophysiology and treatment of acute laminitis. In S.M. Reed, W.M. Bayly \& D.C. Sellon. Equine internal medicine ( $2^{\mathrm{a}}$ ed., pp.522-530). St. Louis, EUA: Saunders.

Tobita, M., Tajima, S. \& Mizuno, H. (2015). Células-tronco mesenquimais derivadas de tecido adiposo e plasma rico em plaquetas: Métodos de transplante de células-tronco que melhoram a estatura. Stem Cell Research \& Therapy, 6(1), 6.

Thomassian, A.; Nicoletti, J.L.M.; Hussni, C.A. \& Alves, A.L.G. (2000). Patofisiologia e tratamento da pododermatite asséptica difusa nos equinos (Laminite equina). Rev. Educ. Contin., 3 (2), 16-29.

Turner, T. A (2020). Diagnostic Imaging. In: G. M. Baxter, G.M, Adams and Stashak's Lameness in Horses (7 ed, pp. 431-438). Hoboken, EUA, WileyBlackwell.

Van Eps, A. W. (2010). Therapeutic Hypothermia (Cryotherapy) to Prevent and Treat Acute Laminitis. The Veterinary clinics of North America. Equine practice, 26(1), 125-133.

Van Eps, A.W.; WalterS, L.J.; Baldwin, G.I.; Mcgarry, M. \& Pollitt, C.C. (2004). Distal limb cryotherapy for the prevention of acute laminitis. Clinical Techniques in Equine PracticE,.3 (1), 64-70.

Vidal, M.A., Kilroy, G.E., Lopez, M.J., Johnson, J.R., Moore, R.M. \& Gimble, J.M. (2007). Characterization of equine adipose tissue-derived stromal cells: Adipogenic and osteogenic capacity and comparison with bone marrow-derived mesenchymal stromal cells. Veterinary Surgery, 36 (7), $613-622$.

Verfaillie, C.M., Pera, M.F. \& Lansdorp, P.M. (2002). Stem Cells: Hype and Reality. Hematology: American Society of Hematology, 2002 (1), 369-391.

Yang, Q. \& Lopez, M.J. (2019). The Equine Hoof: Laminitis, Progenitor (Stem) Cells, and Therapy Development. Toxicologic Pathology, 1-14.

Zago, M.A. \& Covas, D.T. (2004). Pesquisa com células-tronco: aspectos científicos, éticos e morais. Seminário Instituto Fernando Henrique Cardoso, São Paulo, SP, Brasil. 